\title{
Definitions and Concepts on Keratoconus and Ectatic Corneal Diseases: Panamerican Delphi Consensus - A Pilot for the Global Consensus on Ectasias
}

\author{
${ }^{1}$ Renato Ambrósio Jr, ${ }^{2}$ Michael W Belin, ${ }^{3}$ Victor L Perez, ${ }^{4}$ Juan Carlos Abad, ${ }^{5}$ José Alvaro P Gomes
}

\begin{abstract}
Purpose: To establish consensus on definitions and concepts of keratoconus and ectatic corneal diseases by using Delphi approach.

Materials and methods: Seventeen Latin American experts on keratoconus and ectatic corneal diseases participated in a 3-round Delphi panel approach. A web-based 12 question survey was answered by panelists in two rounds, followed by life discussion meeting. A two-third majority strategy was defined as a consensus.
\end{abstract}

Results: Corneal ectatic diseases were defined as progressive thinning conditions without acute stromal inflammation, and were classified as keratoconus, pellucid marginal degeneration (PMD), keratoglobus, and ectasia after trauma or surgery. The pattern of thinning was considered the main aspect for the classification of ectatic diseases, but criteria for staging the disease needs to be improved. Corneal tomography with $3 \mathrm{D}$ reconstruction, distinguished from Placido-disk based front surface topography was elected as the diagnostic procedure currently capable of detecting the earliest clinical ectatic changes. Biomechanical alterations were considered to be the first event for ectasia development. Eye rubbing was directly related to the development and progression of ectasia. Inflammation was considered as a possible event on the physiopathology. Keratoconus was considered as a bilateral disease, with often asymmetric presentation, while ectasia may occur unilaterally if there is significant corneal insult, leading to biomechanical failure. No consensus was achieved for the definitions on forme fruste keratoconus (FFKC).

Conclusion: Consensus was achieved on definitions of corneal ectatic diseases. Disease staging, including criteria for FFKC or subclinical ectasia remains controversial. A larger consensus including experts from different groups around the world is needed.

\footnotetext{
${ }^{1,5}$ Department of Ophthalmology, Federal University of São Paulo, São Paulo, Brazil

${ }^{2}$ Department of Ophthalmology and Vision Science, University of Arizona, Tucson, Arizona, USA

${ }^{3}$ Bascom Palmer Eye Institute, Miami, Florida, USA

${ }^{4}$ Department of Ophthalmology, Universidad de Antoquia Medellin, Colombia
}

Corresponding Author: Renato Ambrósio Jr, Rua Conde de Bonfim 211/712 - 20.520-050, Rio de Janeiro, RJ, Brazil, Phone: 55-2122344233, e-mail: dr.renatoambrosio@gmail.com
Keywords: Keratoconus, Ectasia, Delphi, Questionnaires, Consensus.

How to cite this article: Ambrósio R Jr, Belin MW, Perez VL, Abad JC, Gomes JAP. Definitions and Concepts on Keratoconus and Ectatic Corneal Diseases: Panamerican Delphi ConsensusA Pilot for the Global Consensus on Ectasias. Int J Kerat Ect Cor Dis 2014;3(3):99-106.

Source of support: This work was performed by the PanCone Study Group, affiliated with PanCornea PAAO.

Conflict of interest: None

\section{INTRODUCTION}

Keratoconus and related ectatic diseases of the cornea have been recognized and extensively studied for over 150 years. ${ }^{1}$ However, over the past decades, there were numerous advances on the understanding of the pathophysiology, diagnosis and treatment of such diseases. ${ }^{2}$ The prevalence of keratoconus is classically stated to be $1 / 2,000$ persons $(0.05 \%))^{2,3}$ However, these estimates are improbably low, given current diagnostic techniques. For example, keratoconus and pellucid marginal degeneration had been identified by corneal topography in up to $5 \%$ of candidates for refractive surgery in the mid 1990 's, ${ }^{4,5}$ which was related to a strong self-selection bias, but also likely a high false positive rate on early screening methods. Interestingly, the incidence of ectatic disorders among refractive candidates was reduced to $0.9 \%,{ }^{6}$ which was related to the a higher education level by patients about laser vision correction, improving diagnostic methods for screening and awareness about progressive keratectasia. $^{7}$

The need for more accurate diagnostic techniques was related to the emergence of iatrogenic ectasia after LASIK and PRK. 8 ,9 Also, the advent of collagen crosslinking, ${ }^{10,11}$ which provided the ability to halt the progression of the disease, but increased the need for the accurate identification of mild cases of ectasia. ${ }^{12}$ In addition, new knowledge and diagnostic information has allowed us to reexamine our classification of keratoconus and related ectatic conditions. $^{13}$

Treatment for ectatic corneal disease have also gone through tremendous evolution, including better contact lens fitting ${ }^{14}$ and a move away from full-thickness corneal 
replacement surgery. Penetrating keratoplasty (PKP) had been considered as the primary surgical option, ${ }^{2}$ indicated exclusively to improve vision when glasses and contact lenses failed. However, alternative techniques, such as the implantation of intracorneal ring segments (ICRS) ${ }^{15,16}$ and collagen crosslinking ${ }^{11}$ have changed the paradigm of indicating surgical procedures for ectatic diseases. Also, deep anterior lamellar keratoplasty (DALK) techniques have demonstrated similar visual outcomes as PKP with the important advantage of retaining the host endothelial cells. ${ }^{17,18}$ In addition, refractive procedures, such as phakic intraocular lenses ${ }^{19,20}$ and customized surface ablation ${ }^{21,22}$ have gained increased attention in the management of keratoconus. The combination of multiple modalities, such as customized ablation and crosslinking, have also been proposed. ${ }^{23,24}$ Femtosecond laser technology, which has revolutionized corneal surgery, has been used for different procedures, such as ICRS, ${ }^{25}$ crosslinking, ${ }^{26}$ and

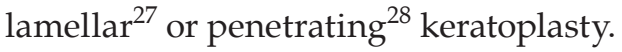

Considering relative high prevalence of ectatic corneal diseases, the increased attention and interest on this area for research, consensus on definitions, classification and staging of the disease are relevant, along with guidelines to treatment. In this study, we proposed to establish a consensus on definition, on keratoconus and ectatic diseases, obtained from a panel of Latin American experts by using the Delphi approach.

\section{MATERIALS AND METHODS}

This study followed the tenets of the Declaration of Helsinki and was designed to elaborate a medical consensus regarding different aspects related to keratoconus and corneal ectatic diseases. The Delphi Panel method was chosen as consensus method. Along with definitions and concepts, there were two other concentration areas in this project: clinical treatment and surgical treatment, which will be detailed in other articles.

For the selection of the panelists group, panelists should be diverse in terms of background, be representative of their geographic location, and have qualification in the area of interest. All the experts who participated on the consensus met every criteria suggested for the panel selection. Based on these three requirements, four inclusion criteria were considered for the selection of panelists:

1. To work as an active licensed ophthalmologist in a Latin American country.

2. To have both local and regional acknowledgement as a cornea expert confirmed by the actual affliation/ position, number of publications, or participation as a speaker in local and international scientific meetings of the subspecialty.
3. To be willing to answer sets of questionnaires that were sent in rounds 1 and 2 .

4. To be willing to participate in a two day meeting in Orlando, FL US (round 3).

For the definitions and concepts arm, 17 panelists were selected from seven different Latin American countries to compose the panel. A contract research organization (CRO), Intrials Pesquisa Clínica (São Paulo, Brazil) was selected to coordinate the deployment of questionnaires and to work as a statistical and Delphi method consultant.

A 12-question questionnaire (Table 1) was created based on clinical experience and practice on the literature related to keratoconus and ectatic diseases. The questionnaire was posted on an access-controlled website, which was sent to panelists who also received a selected bibliographic material for reference. There were 59 scientific articles selected that contained convergent and divergent opinions among each other in order to avoid any kind of answer bias. All articles were selected from a scientific journal with an impact factor above 1 .

For the first round, the panelists had a period of 14 days to respond to the questionnaire electronically using the website, through a private link, which was sent directly to the participants' registered e-mail. After the questionnaire was answered, only the Intrials team responsible for data analysis had access to the answers.

After the first round, data analysis was performed for evaluation of the obtained data. Four new questions were elaborated based on the topics that did not obtain agreement (Table 2). These questions were sent using the same approach for the second round.

The multiple choice questions had three distinct types are as follows:

1. Exclusion criteria, where only one answer should be marked.

2. Inclusion criteria, where one or more options could be marked.

3. Likert's scale with five graded options, being those in order of importance and agreement (e.g. from $1=$ extremely important to $5=$ not important).

For each kind of questions composing the questionnaires, a type of statistical analysis was performed, to achieve an agreement. The consensus was attributed differently to each type of analysis, according to Table 3. A fourth free answer style was used so that terms or values that were similar were compiled.

The two-question rounds were followed by a formal meeting with all panel participants for discussion of all 12 questions. At this moment, participants had the opportunity to observe the generated data about all subjects and discuss if they were or were not in agreement. During the 
Table 1: Questionnaire for round 1

1. Out of the clinical conditions (diseases) below, which would you classify as ectasias?
( ) Keratoconus
( ) Pellucid marginal degeneration
( ) Keratoglobus
( ) Terrien marginal degeneration
( ) Mooren's ulcer
( ) Scleral staphyloma
( ) 'Ectasias' secondary to refractive surgery (LASIK, RK, PRK) or trauma
( ) Warpage

2. On the following assertion: 'Keratoconus, DMP, and keratoglobus are basically the same disease with small variations'
( ) Agree
( ) Disagree

3. Which of the conditions/features below are critical to consider as an ectatic corneal disease?
( ) Thinning
( ) Absence of inflammation
( ) No vascularization
( ) Presence of high-order aberrations
( ) Progressive characters

4. For the diagnosis of ectasia, should be considered (in order of importance to those which you find elevant)
( ) Anamnesis
( ) Measurement of AV
( ) Topography
( ) Tomography
( ) Corneal Biomechanical study

5. For the diagnosis of ectasia, and fundamental (in order of importance to those which you find relevant)
( ) Topographic change
( ) Tomography change
( ) Biomechanical change
( ) Change in aberrometry
( ) Loss of visual acuity

6. On the alteration of early ectasia, this would be detected with
( ) Measurement of AV
( ) Biomicroscopic clinical examination
( ) Topography of cornea
( ) Tomography of cornea
( ) Corneal biomechanical study
( ) Total aberrometry
( ) Corneal aberrometry

7. On the assertion: 'Placid topography characterizes the lacrimal film and anterior surface of the cornea, being distinct from the 3D tomography of cornea that characterizes the anterior and posterior cornea and pachymetry distribution'
( ) Agree
( ) Disagree

8. Of the conditions below, which one(s) would be considered as frusta form of keratoconus?
( ) Eye with slightly altered topography with less inward bending and/or diversion of vectors, stable for over a year, with tomographic evaluation and normal biomechanics
( ) Eye without criteria of keratoconus in topography (Rabinowitz/Klyce/Maeda/Smolek) of patients with keratoconus diagnosed in the contralateral eye
( ) Preoperative state of a case that developed ectasia pos-lasik/PRK identifiable risk factors
( ) Eye criteria without keratoconus in topography (Rabinowitz/Klyce/Maeda/Smolek) of patients who developed keratoconus

9. Do you believe that there may be development of unilateral keratoconus?
( ) Yes
( ) No

10. Do you believe that the act of scratching the eyes is directly related to the emergence of keratoconus?
( ) Yes
( ) No

11. Do you believe that the act of scratching the eyes is directly related to the progression of keratoconus?
( ) Yes
( ) No 
12. About the current staging of keratoconus, which is your preference
( ) Krumeich
( ) Evaluation of keratoconus collaborative longitudinal study (CLEK)
( ) Alió
( ) None the above. I think and need a new staging

13. For the staging of keratoconus, you consider important
( ) VA
( ) Topographical index
( ) Biomechanical index
( ) Aberrometry
( ) Biomicroscopic changes

Table 2: Questionnaire for round 2

1. Out of the clinical conditions (diseases) below, which would you classify as ectasias?
( ) Keratoconus
( ) Pellucid marginal degeneration
( ) Keratoglobus
( ) Terrien marginal degeneration
( ) Mooren's ulcer
( ) Scleral staphyloma
( ) 'Ectasias' secondary to refractive surgery (LASIK, RK, PRK) or trauma
( ) Warpage

2. On the following assertion: 'Keratoconus, DMP, and keratoglobus are basically the same disease with small variations'
( ) Agree
( ) Disagree

3. Which of the conditions/features below are critical to consider as an ectatic corneal disease?
( ) Thinning
( ) Absence of inflammation
( ) No vascularization
( ) Presence of high-order aberrations
( ) Progressive characters

4. For the diagnosis of ectasia, should be considered (in order of importance to those which you find relevant)
( ) Anamnesis
( ) Measurement of AV
( ) Topography
( ) Tomography
( ) Corneal biomechanical study

5. For the diagnosis of ectasia, and fundamental (in order of importance to those which you find relevant)
( ) Topographic change
( ) Tomography change
( ) Biomechanical change
( ) Change in aberrometry
( ) Loss of visual acuity

6. On the alteration of early ectasia, this would be detected with
( ) Measurement of AV
( ) Biomicroscopic clinical examination
( ) Topography of cornea
( ) Tomography cornea
( ) Corneal biomechanical study
( ) Total aberrometry
( ) Corneal aberrometry

7. On the assertion: 'Placid topography characterizes the lacrimal film and anterior surface of the cornea, being distinct from the 3D tomography of cornea that characterizes the anterior and posterior cornea and pachymetry distribution'
( ) Agree
( ) Disagree

8. Of the conditions below, which one(s) would be considered as frusta form of keratoconus?

( ) Eye with slightly altered topography with less inward bending and/or diversion of vectors, stable for over a year, with tomographic evaluation and normal biomechanics 

( ) Eye without criteria of keratoconus in topography (Rabinowitz/Klyce/Maeda/Smolek) of patients with keratoconus diagnosed in the contralateral eye
( ) Preoperative state of a case that developed ectasia pos-lasik/PRK identifiable risk factors
( ) Eye criteria without keratoconus in topography (Rabinowitz/Klyce/Maeda/Smolek) of patients who developed keratoconus

9. Do you believe that there may be development of unilateral keratoconus?
( ) Yes
( ) No

10. Do you believe that the act of scratching the eyes is directly related to the emergence of keratoconus?
( ) Yes
( ) No

11. Do you believe that the act of scratching the eyes is directly related to the progression of keratoconus?
( ) Yes
( ) No

12. About the current staging of keratoconus, which is your preference
( ) Krumeich
( ) Alió
( ) VA
( ) Topographical index
( ) Biomechanical index
( ) Aberrometry
( ) Biomicroscopic changes

( ) Evaluation of keratoconus collaborative longitudinal study (CLEK)

( ) None the above. I think and need a new staging

13. For the staging of keratoconus, you consider important

Table 3: Type of analysis

\begin{tabular}{lll}
\hline Methods & Answer possibility & Consensus \\
\hline $\begin{array}{l}\text { Simple frequency } \\
\text { (F) }\end{array}$ & $\begin{array}{l}\text { only one correct and } \\
\text { excluding answer }\end{array}$ & $\mathrm{F} \geq 66.67 \%$ \\
& -2 choice options & \\
$\begin{array}{l}\text { Adjustment Chi- } \\
\text { square }(p)\end{array}$ & $\begin{array}{l}\text { one answer possibility, } \\
\text { excluding, with 3 or more } \\
\text { categories }\end{array}$ & \\
Cronbach alpha $(\alpha)$ & $\begin{array}{l}\text { Likert's scale } \\
\text { (grading from 1 to 5) }\end{array}$ & $\alpha \geq 0.05$ \\
\hline
\end{tabular}

discussion, the agreement strategy was established by the choice of an answer option by the majority of participants (above 67\%). The meeting was initiated with a presentation of the consensus project rationale and objectives as well as clarifying the Delphi Panel methodology used in the project. A CRO was responsible for data presentation to each in rounds 1 and 2 and for coordinating group voting, in the case of questions without agreement. The discussion was mediated with no intent to persuade the participants on the voting processes for disagreement cases.

\section{RESULTS}

The clinical conditions (diseases) classified as ectasia were: keratoconus (100\% agreement), pellucid marginal degeneration (PMD - 94\% agreement), and keratoglobus ( $94 \%$ agreement). Ectasia after trauma or surgery was included in round 3 with 100\% agreement. Contact lens induced warpage, Terrien's marginal degeneration, Mooren's ulcer and staphyloma were not considered as ectatic diseases.
For consideration as an ectatic cornea disease, the fundamental characteristic was progressive thinning ( $94 \%$ agreement). The absence of acute stromal inflammation was included in round 3 as a necessary characteristic for ectasia. Lack of vascularization and presence of high order aberrations were not considered as fundamental characteristics for ectasia.

The following affirmation was considered as true and valid (94\% agreement): 'Placido topography characterizes the front corneal surface and the tearfilm, being distinct from three-dimensional (3D) cornea tomography, which characterizes the anterior and posterior corneal surfaces and pachymetric distribution'.

After discussions in round 3, corneal biomechanical alterations were considered as the first event on ectasia development (100\% agreement), followed by thinning, protrusion, inductions of ocular aberrations and loss of high contrast visual acuity. However, considering diagnosis of ectasia, corneal tomography (CTm) was elected as the most important exam, followed by corneal topography, clinical anamnesis, corneal biomechanical assessment and visual acuity.

The only aspect that distinguishes between keratoconus, PMD and keratoglobus was the thinning location and pattern (100\% agreement). Age of onset, astigmatism pattern, strategy for contact lens fitting, prognosis and surgical planning were not considered as characteristics that enable the characterization of the type of ectatic disease (less than 65\% agreement).

No consensus was achieved for the method of staging keratoconus and ectatic diseases. The sentence 'The 
staging and severity criteria for keratoconus and ectatic disease needs to be revised' was considered as valid with $94 \%$ agreement. Eye rubbing was directly related to the disease appearance and progression with 100\% agreement on round 3. Inflammation was considered as a possible event, which may be associated to the physiopathology of ectatic diseases on the cornea ( $94 \%$ agreement).

Keratoconus was considered as a bilateral disease, but with a very asymmetric evolution ( $94 \%$ agreement). However, ectasia may occur in only one patient's eye if there is enough trauma or insult that leads to biomechanical decompensation (100\% agreement).

Noconsensus for definition of forme fruste keratoconus (FFKC - less than 65\% agreement) was obtained so the conditions described below were not considered as such:

- 'Corneal topography slightly altered, with inferior steepening and/or skewed radial axis, but stable for more than a year, with normal tomography and biomechanical evaluations.'

- 'Eye without clinical keratoconus, including topography criteria (Rabinowitz and Klyce/Maeda/ Smolek), of patient diagnosed with keratoconus in the contralateral eye.'

- 'Preoperative stage of a case that developed postlasik/PRK ectasia without identifiable risk factors'.

- 'Eye without clinical keratoconus, including topography criteria (Rabinowitz and Klyce/Maeda/ Smolek) of patient that developed natural keratoconus progression.'

\section{DISCUSSION}

Formal consensus methods represent a possible solution for medical and health areas. Its main purpose is to define opinion agreement levels about controversial issues, ${ }^{29}$ mainly when unanimity of opinions does not exist because of a lack of, or, contradictory scientific evidences. The Delphi panel is one of the methodologies used for reaching consensus. It was created in 1948, as a way of obtaining opinion from experts in a systematic way. ${ }^{29}$ The Delphi panel has been used for other areas such as Dysfunctional TearSyndrome(DTS), ${ }^{30}$ and ocular allergy. ${ }^{31}$

In this Delhi panel, a panel of experts on cornea and refractive surgery was selected to obtain a consensus based on current knowledge about keratoconus and ectatic diseases. At the present time, there is no medical consensus for many aspects related to the concepts and definitions of keratoconus and ectatic corneal diseases. This is relevant for the ophthalmological-scientific community considering the fast improvements related to understanding as well as for the clinical and surgical treatments of such diseases.
The consensus related to many aspects of the definitions of keratoconus and related ectatic diseases of the cornea have been in agreement with classic literature. ${ }^{1,2}$ The recognition of tomography as being distinct from topography was a very important aspect of this panel, which has been recently proposed. ${ }^{32}$ While it is well recognized that corneal topography introduced the capability to diagnose the disease prior to the development of gross biomicroscopic signs or loss of significant best spectacle-corrected vision, ${ }^{6,33}$ corneal tomography further demonstrated an enhanced sensitivity for diagnosing the earliest forms of disease, ${ }^{12}$ which has been found critical to prevent keratectasia after refractive elective procedures, such as LASIK. ${ }^{8}$

The ability for clinical biomechanical assessment also gained momentum for the diagnosis of ectatic diseases. ${ }^{34,35}$ Interestingly, there was consensus that corneal biomechanical alterations represent the first event of ectasia development, but clinical biomechanical assessment is not yet the exam capable of identifying the mildest ectatic changes on the cornea. While this represents an area of very active research, new diagnostics for dynamically characterizing corneal deformation response using Scheimpflug, ${ }^{36,37}$ or OCT $^{38}$ may demonstrate clinical usefulness for biomechanical testing in the future.

Wavefront analysis has been used for keratoconus diagnosis ${ }^{39}$ and also to guide therapeutics, such as the prescription of glasses, ${ }^{40}$ or even to enable customized soft contact lenses. ${ }^{41,42}$ However, the emergence of higher order aberrations and visual impairment were considered as later changes that occur during ectasia.

Evaluation of disease severity and staging was evaluated by the collaborative longitudinal evaluation of keratoconus (CLEK) study. ${ }^{43,45}$ Nevertheless, this is an area that needs more studies considering complementary studies, such as tomography, topography and clinical presentation as no consensus was achieved for the method for staging keratoconus and ectatic diseases.

Eye rubbing was directly related to the disease appearance and progression, which is in agreement with current literature. ${ }^{46,48}$ Inflammation was considered as a possible event which may be associated to the physiopathology of ectasia. ${ }^{49}$

Keratoconus was considered as a bilateral disease, but with a very asymmetric evolution, with $94 \%$ agreement. There was consensus also that ectasia may occur in only one patient's eye if there is enough trauma (such as eye rubbing $)^{50-52}$ or insult, such as refractive surgery, ${ }^{53}$ that leads to biomechanical decompensation $(100 \%$ agreement). No consensus in definitions of forme fruste keratoconus, including the one proposed by $\mathrm{Klyce}^{54}$ or the original one by Amsler. ${ }^{55}$ 
The task of finding consensus on definitions related to keratoconus and ectatic corneal diseases was relatively complex. The current Delphi panel successfully determined consensus on many relatant topics. However, a larger and global consensus including experts from different groups around the world is needed to further improve many controversial topics, especially an internationally acceptable staging criteria and a more rationale algorithm of treatment for these diseases.

\section{REFERENCES}

1. Krachmer JH, Feder RS, Belin MW. Keratoconus and related noninflammatory corneal thinning disorders. Surv Ophthalmol 1984;28(4):293-322.

2. Rabinowitz YS. Keratoconus. Surv Ophthalmol 1998;42(4): 297-319.

3. Kennedy RH, Bourne WM, Dyer JA. A 48-year clinical and epidemiologic study of keratoconus. Am J Ophthalmol 1986; 101(3):267-273.

4. Nesburn AB, Bahri S, Salz J, et al. Keratoconus detected by videokeratography in candidates for photorefractive keratectomy. J Refract Surg 1995;11(3):194-201.

5. Wilson SE, Klyce SD. Screening for corneal topographic abnormalities before refractive surgery. Ophthalmology 1994; 101(1):147-152.

6. Ambrosio R Jr, Klyce SD, Wilson SE. Corneal topographic and pachymetric screening of keratorefractive patients. J Refract Surg 2003;19(1):24-29.

7. Seiler $\mathrm{T}$, Quurke AW. Iatrogenic keratectasia after LASIK in a case of forme fruste keratoconus. J Cataract Refract Surg 1998;24(7):1007-1009.

8. Ambrosio R Jr, Randleman JB. Screening for ectasia risk: what are we screening for and how should we screen for it? J Refract Surg 2013;29(4):230-232.

9. Ambrosio R Jr, Nogueira LP, Caldas DL, et al. Evaluation of corneal shape and biomechanics before LASIK. Int Ophthalmol Clin 2011;51(2):11-38.

10. Koller T, Mrochen M, Seiler T. Complication and failure rates after corneal crosslinking. J Cataract Refract Surg 2009; 35(8):1358-1362.

11. Wollensak G, Spoerl E, Seiler T. Riboflavin/ultravioletA-induced collagen crosslinking for the treatment of keratoconus. Am J Ophthalmol 2003;135(5):620-627.

12. Saad A, Gatinel D. Topographic and tomographic properties of forme fruste keratoconus corneas. Invest Ophthalmol Vis Sci 2010;51(11):5546-5555.

13. Belin MW, Asota IM, Ambrosio R Jr, Khachikian SS. What's in a name: keratoconus, pellucid marginal degeneration, and related thinning disorders. Am J Ophthalmol 2011;152(2):157$162 \mathrm{e} 1$.

14. Jhanji V, Sharma N, Vajpayee RB. Management of keratoconus: current scenario. Br J Ophthalmol 2011;95(8):1044-1050.

15. Colin J, Cochener B, Savary G, Malet F. Correcting keratoconus with intracorneal rings. J Cataract Refract Surg 2000;26(8):1117-1122.

16. Ferrara G, Torquetti L, Ferrara P, Merayo-Lloves J. Intrastromal corneal ring segments: visual outcomes from a large case series. Clin Experiment Ophthalmol 2012 Jul;40(5):433-439.

17. Ashar JN, Pahuja S, Ramappa M, Vaddavalli PK, Chaurasia S, Garg P. Deep anterior lamellar keratoplasty in children. Am J Ophthalmol 2013;155(3):570-574 e1.
18. Smadja D, Colin J, Krueger RR, et al. Outcomes of deep anterior lamellar keratoplasty for keratoconus: learning curve and advantages of the big bubble technique. Cornea 2012;31(8):859-863.

19. Venter J. Artisan phakic intraocular lens in patients with keratoconus. J Refract Surg 2009;25(9):759-764.

20. Kamiya K, Shimizu K, Ando W, Asato Y, Fujisawa T. Phakic toric implantable collamer lens implantation for the correction of high myopic astigmatism in eyes with keratoconus. J Refract Surg 2008;24(8):840-842.

21. Hardten DR, Gosavi VV. Photorefractive keratectomy in eyes with atypical topography. J Cataract Refract Surg 2009;35(8):1437-1444.

22. Koller T, Iseli HP, Donitzky C, Ing D, Papadopoulos N, Seiler T. Topography-guided surface ablation for forme fruste keratoconus. Ophthalmology 2006;113(12):2198-2202.

23. Kanellopoulos AJ. Comparison of sequential vs same-day simultaneous collagen cross-linking and topography-guided PRK for treatment of keratoconus. J Refract Surg 2009;25(9): S812-818.

24. Krueger RR, Kanellopoulos AJ. Stability of simultaneous topography-guided photorefractive keratectomy and riboflavin/UVA cross-linking for progressive keratoconus: case reports. J Refract Surg 2010;26(10):S827-832.

25. Pinero DP, Alio JL, El Kady B, et al. Refractive and aberrometric outcomes of intracorneal ring segments for keratoconus: mechanical versus femtosecond-assisted procedures. Ophthalmology 2009;116(9):1675-1687.

26. Kanellopoulos AJ. Collagen cross-linking in early keratoconus with riboflavin in a femtosecond laser-created pocket: initial clinical results. J Refract Surg 2009;25(11):1034-1037.

27. Buzzonetti L, Laborante A, Petrocelli G. Refractive outcome of keratoconus treated by combined femtosecond laser and big-bubble deep anterior lamellar keratoplasty. J Refract Surg 2011;27(3):189-194.

28. Chamberlain WD, Rush SW, Mathers WD, Cabezas M, Fraunfelder FW. Comparison of femtosecond laser-assisted keratoplasty versus conventional penetrating keratoplasty. Ophthalmology 2011;118(3):486-491.

29. Fink A, Kosecoff J, Chassin M, Brook RH. Consensus methods: characteristics and guidelines for use. Am J Public Health 1984;74(9):979-983.

30. Behrens A, Doyle JJ, Stern L, et al. Dysfunctional tear syndrome: a Delphi approach to treatment recommendations. Cornea 2006;25(8):900-907.

31. Santos MS, Alves MR, Freitas D, et al. Ocular allergy Latin American consensus. Arq Bras Oftalmol 2011;74(6):452-456.

32. Ambrosio R, Jr., Belin MW. Imaging of the cornea: topography vs tomography. J Refract Surg 2010;26(11):847-849.

33. Maeda N, Klyce SD, Tano Y. Detection and classification of mild irregular astigmatism in patients with good visual acuity. Surv Ophthalmol 1998;43(1):53-58.

34. Luce DA. Determining in vivo biomechanical properties of the cornea with an ocular response analyzer. J Cataract Refract Surg 2005;31(1):156-162.

35. Fontes BM, Ambrosio R Jr, Jardim D, Velarde GC, Nose $\mathrm{W}$. Corneal biomechanical metrics and anterior segment parameters in mild keratoconus. Ophthalmology 2010; 117(4): 673-679.

36. Ambrosio R Jr, Valbon BF, Faria-Correia F, Ramos I, Luz A. Scheimpflug imaging for laser refractive surgery. Curr Opin Ophthalmol 2013;24(4):310-320. 
37. Ambrósio Jr R, Ramos I, Luz A, et al. Dynamic ultra high speed Scheimpflug imaging for assessing corneal biomechanical properties. Revista Brasileira de Oftalmologia 2013;72(2):99-102.

38. Dorronsoro C, Pascual D, Perez-Merino P, Kling S, Marcos S. Dynamic OCT measurement of corneal deformation by an air puff in normal and cross-linked corneas. Biomed Opt Express 2012;3(3):473-487.

39. Jafri B, Li X, Yang H, Rabinowitz YS. Higher order wavefront aberrations and topography in early and suspected keratoconus. J Refract Surg 2007;23(8):774-781.

40. Ambrósio R Jr, Caldas DL, Silva RSd, Pimentel LN, Valbon BdF. Impacto da análise do 'wavefront' na refratometria de pacientes com ceratocone. Revista Brasileira de Oftalmologia 2010;69(5):294-300.

41. Matos L, Carvalho LA. [Preliminary results of an algorithm for customized soft contact lens ablation]. Arq Bras Oftalmol 2009;72(2):174-179.

42. Katsoulos C, Karageorgiadis L, Vasileiou N, Mousafeiropoulos $\mathrm{T}$, Asimellis G. Customized hydrogel contact lenses for keratoconus incorporating correction for vertical coma aberration. Ophthalmic Physiol Opt 2009;29(3):321-329.

43. Wagner H, Barr JT, Zadnik K. Collaborative Longitudinal Evaluation of Keratoconus (CLEK) Study: methods and findings to date. Cont Lens Anterior Eye 2007;30(4):223-232.

44. McMahon TT, Szczotka-Flynn L, Barr JT, et al. A new method for grading the severity of keratoconus: the Keratoconus Severity Score (KSS). Cornea 2006;25(7):794-800.

45. Zadnik K, Barr JT, Edrington TB, et al. Corneal scarring and vision in keratoconus: a baseline report from the
Collaborative Longitudinal Evaluation of Keratoconus (CLEK) Study. Cornea 2000;19(6):804-812.

46. Jafri B, Lichter H, Stulting RD. Asymmetric keratoconus attributed to eye rubbing. Cornea 2004;23(6):560-564.

47. Krachmer JH. Eye rubbing can cause keratoconus. Cornea 2004;23(6):539-540.

48. McMonnies CW. Abnormal rubbing and keratectasia. Eye Contact Lens 2007;33(6):265-271.

49. Lema I, Duran JA. Inflammatory molecules in the tears of patients with keratoconus. Ophthalmology 2005;112(4):654659.

50. Diniz CM, Tzelikis PF, Rodrigues Junior A, Alvim Hda S, Dantas RR, Figueredo AR. Unilateral keratoconus associated with continual eye rubbing due to nasolacrimal obstructioncase report. Arq Bras Oftalmol 2005;68(1):122-125.

51. Ioannidis AS, Speedwell L, Nischal KK. Unilateral keratoconus in a child with chronic and persistent eye rubbing. Am J Ophthalmol 2005;139(2):356-357.

52. Lindsay RG, Bruce AS, Gutteridge IF. Keratoconus associated with continual eye rubbing due to punctal agenesis. Cornea 2000;19(4):567-569.

53. Ambrosio R Jr, Dawson DG, Salomao M, Guerra FP, Caiado AL, Belin MW. Corneal ectasia after LASIK despite low preoperative risk: tomographic and biomechanical findings in the unoperated, stable, fellow eye. J Refract Surg 2010;26(11): 906-911.

54. Klyce SD. Chasing the suspect: keratoconus. Br J Ophthalmol 2009;93(7):845-847.

55. Amsler M. The 'forme fruste' of keratoconus. Wien Klin Wochenschr 1961;73:842-843. 